\title{
Brief Analysis of Strategies to Improve English Listening Comprehension Competence among Non-English Undergraduate Students
}

\author{
Huaru Chen \\ Foreign Language Department, The University of Suwon \\ 445-743 San 2-2 Wau-ri, Bongdan-eup, Hwaseong-si, Gyeonggi-do, Korea \\ \& Foreign Language School, Linyi University \\ Linyi 276005, Shandong, China \\ E-mail: chenhuaru81@163.com
}

Received: June 21, 2011

Accepted: July 17, $2011 \quad$ Published: December 1, 2011

doi:10.5539/ass.v7n12p68

URL: http://dx.doi.org/10.5539/ass.v7n12p68

\begin{abstract}
The status quo of English listening comprehension of non-English undergraduate students is worrying. In this article, the author put forward some effective strategies to practically improve the English listening comprehension of non-English undergraduate students by taking into consideration of some practical experiences in the college English teaching for several years and based on this status quo.
\end{abstract}

Keywords: Listening comprehension competence, College English, Non-English major

\section{Introduction}

Listening comprehension competence is an important means in speech communication and is also the most frequently used perceptive function in the daily life of human being. It can be said that, there is approximately $50 \%$ of the time when a normal adult uses the perceptive function of "listening" in the speech communication, as only if the speech intention of the communication target is correctly comprehended, can one give correspondingly decent speech feedback and finish a satisfying speech communication process. In the process of English learning, cultivation of listening comprehension competence should not be ignored since good listening comprehension may help you enhance your English knowledge and improve your communicative competence in English.

For a long time, quite a large number of people have held a wrong opinion in teaching of college English that, listening comprehension is a process in which one passively acquires information, which requires no skill and in which the more one listens, the greater the listening comprehension competence. However, it is not the case. Listening comprehension contains the two major aspects of "listening" and "comprehension". "Listening" is to receive, memorize and repeat the sound wave of the voice. "Comprehension" is to explain what one has listened to (Zhang Delu and Miao Xingwei et al, 2005). Thus, the listening comprehension process is a positive yet complex process. That is to say, listening comprehension is a process from perception to analysis and then to application. It is the overall reflection of the knowledge in English. It should not be denied that, much listening indeed is a positive means to enhance the listening comprehension competence, but it calls for perfect teaching methods to attain an ideal effect. This article aims to find out interference factors that affect the listening comprehension and discuss feasible and effective teaching methods and strategies to improve the English listening comprehension competence among non-English undergraduate students.

\section{Factors that affect improvement of listening comprehension and resolution methods}

\subsection{Appropriate selection of listening materials and suitable difficulty}

Appropriate selection of listening materials is of critical importance. If the listening materials are too difficulty, it might cause those non-English undergraduate students with low English proficiency to be frustrated in the process of learning English, which may further make them lose confidence in their own listening comprehension competence and may even give rise to their sentiment of boredom in the listening course. On the contrary, if the 
listening materials are too easy, it might make the students feel tedious and have no interest in learning English. Thus, appropriate selection of listening materials is both the foundation of teaching listening but also an important aspect. Selection of materials that consistent with the existing English level of non-English undergraduate students and training of listening skills with pertinence help to stimulate students' feeling of thirst for knowledge, which can then achieve the purpose of exercise. For instance, it is suitable for freshmen in the universities to select some voice materials that are close to the realistic life to listen to, and it is not proper for them to listen to those voice materials with strong science popularity which are relatively abstract.

\subsection{To eliminate the emotion of intension and to exercise with relaxation}

The emotional condition of students in doing exercise of listening is a subjective element to affect the effect of listening comprehension. In the practical teaching, it is not difficult for us to discover that some students are unquestionable whether in terms of their vocabulary or in terms of their competence in grammar, but their listening comprehension competence is far inferior. The reason is nothing more than that these students are excessively intense and are extremely afraid that they might make a mistake. Specifically speaking, under the circumstance when students do not possess positive listening motive and self-confidence, it is often that their attention is likely to be dispersed, which may interfere the listening process. Therefore, in teaching of listening, it is also of great importance to help students alleviate the intense emotion and build a relaxed training atmosphere.

\section{To improve learning methods and to enhance listening comprehension competence}

Training of listening comprehension competence is not to blindly listen without any choice. Instead, it requires appropriate methods and to go from shallow to deep. The listening methods that are frequently used include the following four: to guess, to keep to the point, to anticipate and to take notes.

\subsection{To guess}

In activities of English listening, we often encounter some strange words or ambiguous and vague speech signals. For instance, in oral communication, those who speak English as a native language often subconsciously use successively local accents, which, together with the noisy background music, causes great difficulty to the listeners. It is quite difficult to hear them clearly. At this time, it is necessary for students to turn to apply the information they have acquired to make a rapid judgment and guess. First of all, they may guess the part of speech of a word according to the knowledge of grammatical structure. If it is a noun, then it is possible that it refers to a person, a thing or a matter. If it is a verb, then it expresses a state or an action. Then, the students may guess the meaning of a word according to the context. For example, there is such a conversion as follows:

Interviewer: Can you explain to me how film editing works?

Film Editor: There are different steps. 'Synching up', for example.

When the listeners hear these two sentences, they would think about the meaning of the phrase 'Synching up'. According to the preceding part of the text, the listeners can guess that this phrase has something to do with film editing, but they are still at a loss. The listeners would find out the answer with relaxation when they continue to listen to the following conversation.

Interviewer: What do you mean by synching up?

Film Editor: It means matching sound and pictures and that is usually done by my assistant... (He Qixin, Jin Limin \& et al., 1993)

Therefore, in the process of doing exercise of English listening, students should not immediately go to look up for the dictionary when they hear some new words or ambiguous or vague phrases. Instead, teachers should lead students in a correct way to try to guess the meanings and make a rapid judgment.

\subsection{To anticipate}

To anticipate means that the listeners use the existing knowledge to make judgment on the content to be listened to. There often occurs such a situation in communication with a mother tongue: even if a speaker still does not finish his words, the listener has already judged the following words the speaker is going to say. Under such as a circumstance, the listener occupies the superiority of the communication. In a communication in English, if a listener can anticipate what a speaker is going to say, then the listener is able to gain more time for himself/herself to organize more appropriate and decent language to respond. Anticipation can help listeners to take the initiative to imagine, infer and judge and actively play the individual initiative, which is helpful for the listeners to comprehend the content they have heard. Therefore, in teaching of English listening, it is necessary to consciously cultivate the ability of students to anticipate. There are two elements that affect the ability of anticipation. In the first place, how much students know about the topic discussed, the surrounding environment 
and the cultural background of the language they speak? For example, the subject of the listening material is "At the Restaurant". If the students happen to have experience in having a diet in a western restaurant or if they have learned about the dietary habits of westerners, then they are able to make active and reasonable inference with the existing knowledge. In this way, when they listen to the material, they are able to comprehend any conversation between the restaurant server and a customer with relaxation. Thus, in teaching of English listening, teachers have to strengthen teaching of knowledge in cultural background so as to gain the effect that what happens is without extra effort. In the second place, how many revelatory phrases or sentences there are in the listening materials? A large majority of listening materials contain implication speeches that can help students to anticipate. For example, when we hear such a phrase as "in other words, or if I can just sum up ...", we can predict that the speaker is going to make a summary on the information he has offered. In addition, the phrase "on the other hand; or and yet..." implies that the speaker is going to propose an opinion or speech that is opposite to the preceding part of the text, and it is not difficult for students to predict what the speakers is going to say by connecting the phrase with the preceding part of the text. Those students who are good at predicting can often infer the content and proper nouns that are generally involved in the listening materials and the questions to be proposed through predication when they listen to a discourse. In this way, they are able to gain control over the game, know fairly well about the discourse to be listened to and answer a question with high proficiency.

\subsection{To keep to the point}

Whether in a realistic speech communication or in a simulation speech communication in the classroom, it is absolutely impossible for the listener not to miss even a word about all the speech information that the speaker has offered. Thus, in teaching of English listening, it is necessary for teachers to teach students how to screen speech information and keep to the point. Only if students can judge what is important and what is not and what is related and what is not, can they grasp the central idea of the listening materials and comprehend the entire text. Then, how to screen the speech information in an accurate way? Firstly, students ought to listen with a purpose. They should bear in mind such a question all the time "What does it mainly talk about?" and look for the answer to the question when they listen to the material. If the text they listen to is a narrative one, then they have to find out the reason of the story, the major clue of the story and the leading character of the story. If they listen to a news report, it is enough for them to know about the time, place and main process of an incident. Secondly, the first sentence of a paragraph and a transitional phrase are also the targets that students ought to grasp. The first sentence of a paragraph is, in most cases, the topic sentence that expresses the central idea of the paragraph and it tells students about the content of the text in a concise way and to the point, whereas a transitional phrase expresses the train of thought of a speaker. Such speeches indicating time, space, example listing, comparison and conclusion in a discourse can all help students accurately master the related information that supports the central idea. All these speeches have an effect on comprehension of the entire discourse that can't be neglected. Thus, in training of listening comprehension, it is not a must that students are required to understand each phrase and each sentence. Instead, comprehension of the major content in the listening materials is the primary purpose of the listening exercise.

\subsection{To take notes}

To take notes is an effective method that helps students to accurately record details of a discourse with relatively great length. Even students who have perfect memory have difficulty in memorizing all details in a long text or conversation, such as, name of a person, name of a place, time, age, price and so on. This, without doubt, may affect correct understanding of students in the listening materials. Therefore, in the process of teaching, what we advocate is to ask students to take advantage of the peculiar respiratory standstill and rhythm in English in the process of listening the tape and grasp the opportunity to quickly write down useful information. In this way, when we make an overall analysis of the entire discourse, we can ask students to take notes to immediately stimulate their existing memory and have a correct understanding of the discourse.

\section{Conclusion}

To sum up, listening comprehension competence is an important component of English communicative competence, an important perceptive function for people to actively acquire speech information and the foundation to determine whether speech communication is successful or not. However, cultivation of the listening comprehension competence is not achieved within one day. Instead, it requires diligent efforts and feasible and effective learning methods and calls for persistent training that is accumulated over a long period and little by little. In teaching of English listening, the teachers ought to fully play the role as a facilitator in that they should teach students the methods to improve their listening comprehension competence and train students' 
learning autonomy and initiative. Nonetheless, it is still a subject that requires us to continuously make explorations how to actually improve the English listening comprehension competence of non-English undergraduate students.

\section{References}

Bao, Lulu. (2010). The Exploration and Design of Listening Teaching Strategies in the CET-4. China Electric Power Education, (11):223-224.

Gao, Lihua. (2003). Discussion on Teaching Method of English Listening. Foreign Language Teaching \& Research in Basic Education, (6):29-31.

He, Qixin \& Jin, Limin et al. (1993). LISTEN TO THIS: 2 (Book for Teachers). Beijing: Foreign Language Teaching and Research Press.

Song, Deru \& Kong, Kai. (2005). Reading of New Ideas in Modern Education. Hefei: Anhui University Press.

Wang, Shouyuan \& Miao, Xingwei. (2003). Teaching EFL Listening: From Theory to Practice. Education Technology for Foreign Language Teaching, (4):1-5.

Zhang, Delu \& Miao, Xingwei et al. (2005). Functional Linguistics and Foreign Language Teaching. Beijing: Foreign Language Teaching and Research Press. 